\title{
LAMOTRIGINE IMPROVES CEREBRAL OUTCOME AFTER HYPOTHERMIC CIRCULATORY ARREST: A STUDY IN A CHRONIC PORCINE MODEL
}

Vesa Anttila, MD

Jussi Rimpiläinen, $\mathrm{MD}^{\mathrm{a}}$

Matti Pokela, MS

Kai Kiviluoma, $\mathrm{MD}, \mathrm{PhD}^{\mathrm{b}}$

Minna Mäkiranta, $\mathrm{MSc}^{\mathrm{c}}$

Ville Jäntti, MD, $\mathrm{PhD}^{\mathrm{c}}$

Vilho Vainionpää, $\mathrm{MD}, \mathrm{PhD}^{\mathrm{b}}$

Jorma Hirvonen, $\mathrm{MD}, \mathrm{PhD}^{\mathrm{d}}$

Tatu Juvonen MD, PhD
Background: Glutamate excitotoxicity has an important role in the development of brain injury after prolonged hypothermic circulatory arrest. The goal of the present studies was to determine the potential efficacy of lamotrigine, an $\mathrm{Na}^{+}$channel blocker, to mitigate cerebral injury after hypothermic circulatory arrest.

Methods: Sixteen pigs (21-27 kg) were randomly assigned to receive lamotrigine $(20 \mathrm{mg} / \mathrm{kg})$ or placebo in a blinded fashion before a 75 -minute period of hypothermic circulatory arrest $\left(20^{\circ} \mathrm{C}\right)$. Hemodynamic, electroencephalographic, and metabolic monitoring were carried out. S-100 $\beta$ protein was determined up to the first postoperative morning. Daily behavioral assessment was performed until the animal died or was put to death on day 7. Histologic analysis of the brain was carried out in all animals.

Results: Complete behavioral recovery was seen in 5 of $8(63 \%)$ animals after lamotrigine administration, compared with 1 of $8(13 \%)$ in the placebo group $(P=.02)$. Among the animals that survived for 7 days, the median behavioral score was higher in the lamotrigine group ( 8 vs $7, P=.02$ ). The medians of recovered electroencephalographic bursts in the lamotrigine group were higher than those in the placebo group $4 \frac{1}{2}$ hours after the start of rewarming $(P=.01)$. The median $\mathrm{S}-100 \beta$ level was lower in the lamotrigine group $(0.01 \mu \mathrm{g} / \mathrm{L})$ than in placebo controls $(0.1 \mu \mathrm{g} / \mathrm{L}) 20$ hours after the start of rewarming $(P=.01)$. The median of total histopathologic score was 5.5 in the lamotrigine group and 7.5 in the placebo group $(P=.06)$.

Conclusions: The present data suggest that lamotrigine improves neurologic outcome after a prolonged period of hypothermic circulatory arrest. (J Thorac Cardiovasc Surg 2000;120:247-55)
$\mathrm{H}$ ypothermic circulatory arrest (HCA) is a frequently used method of cerebral protection during opera-

From the Departments of Surgery and Anesthesiology ${ }^{\mathrm{b}}$ and the Laboratory of Clinical Neurophysiology, ${ }^{\mathrm{c}}$ Oulu University Hospital, and the Department of Forensic Medicine, ${ }^{\mathrm{d}}$ University of Oulu, Oulu, Finland.

These studies were supported by grants from Oulu University Hospital and the Finnish Foundation for Cardiovascular Research. Dr Juvonen was supported by the Ingegerd and Viking Olov Björk Scholarship for Cardiothoracic Research.

Received for publication Oct 5, 1999; revisions requested Dec 13, 1999; revisions received Feb 29, 2000; accepted for publication Feb 29, 2000.

Address for reprints: Tatu Juvonen, $\mathrm{MD}, \mathrm{PhD}$, Department of Surgery, Oulu University Hospital, FIN 90220 Oulu, Finland (Email: tatu.juvonen@oulu.fi).

Copyright (c) 2000 by The American Association for Thoracic Surgery

0022-5223/2000 $\$ 12.00+0 \quad \mathbf{1 2 / 1 / 1 0 6 8 3 4}$

doi: $10.1067 / \mathrm{mtc} .2000 .106834$ tions on the aortic arch. ${ }^{1,2}$ Its main limitation is the time constraint. At a brain temperature of $10^{\circ} \mathrm{C}$ to $15^{\circ} \mathrm{C}, 10 \%$ to $20 \%$ of the baseline cerebral metabolic rate of oxygen $\left(\mathrm{CMRO}_{2}\right)$ is left and the onset of permanent injury is delayed 40 to 50 minutes. ${ }^{3}$ Selective antegrade cerebral perfusion and retrograde cerebral perfusion are other strategies used for brain protection during aortic arch surgery. Unfortunately, not all expectations addressed to these methods have been fulfilled, leading to renewed interest in the search for other methods to increase the permissible period of HCA.

A biochemical cascade in the failure of neurotransmitters has been demonstrated to be a crucial link in the pathogenesis of ischemic brain injury. ${ }^{4-6}$ Glutamate accumulates in the intercellular space and acts as a neurotoxic substance. It opens calcium channels, leading to an influx of calcium, which starts the catastrophic cascade that eventually leads to neuronal autodigestion and 
cell death. ${ }^{6}$ Better understanding of these biochemical mechanisms of cerebral damage has opened new therapeutic windows to improve brain protection when normal antegrade cerebral perfusion is compromised.

Lamotrigine (3,5-diamino-6-[2,3-dichlorophenyl]1,2,4-triazine) is an $\mathrm{Na}^{+}$channel blocker used clinically as an antiepileptic drug. It has few side effects and can be administered orally. In view of the interaction of lamotrigine with $\mathrm{Na}^{+}$channels and its ability to penetrate the blood-brain barrier, interest has been focused on its neuroprotective properties. In an experimental study of global cerebral ischemia in a rabbit model, glutamate concentrations in animals receiving lamotrigine were significantly lower than in the controls. ${ }^{7} \mathrm{~A}$ study in gerbils showed a neuroprotective effect of lamotrigine after global ischemia. ${ }^{8}$

The aim of this study was to test the neuroprotective efficacy of lamotrigine during HCA in a chronic porcine model.

\section{Materials and methods}

Sixteen female juvenile (8- to 10 -week-old) pigs of a native stock, weighing 21 to $27 \mathrm{~kg}$, were randomly assigned to receive either lamotrigine or saline solution before a 75minute period of $\mathrm{HCA}$ at $20^{\circ} \mathrm{C}$.

Preoperative management. All animals received humane care in accordance with the "Principles of Laboratory Animal Care" formulated by the National Society for Medical Research and the "Guide for the Care and Use of Laboratory Animals" prepared by the Institute of Laboratory Animal Resources and published by the National Institutes of Health (NIH publication No. 85-23, revised 1985). The study was approved by the Research Animal Care and Use Committee of the University of Oulu.

Drug administration. An isethionate (2-hydroxyethanesulfonate) salt of lamotrigine (3,5-diamino-6-[2,3dichlorophenyl]-1,2,4-triazine) was diluted in saline solution to obtain a solution containing lamotrigine at $50 \mathrm{mg} / \mathrm{mL}$, and this was packed in 10-mL ampules in the pharmaceutical laboratory of our institution. Saline placebo ampules were prepared similarly. A dose of $20 \mathrm{mg} / \mathrm{kg}$ was measured and diluted to $50 \mathrm{~mL}$ in saline solution. This volume was given intravenously over a period of 20 minutes, starting 2 hours before HCA. Randomization was carried out by the chemist in the pharmaceutical laboratory, and the codes were broken after the entire series of experiments were accomplished. Therefore, all observers in every data recording point were unaware of whether the animal was a lamotrigine subject or a control subject.

Anesthesia and hemodynamic monitoring. Anesthesia was induced with ketamine hydrochloride $(10 \mathrm{mg} / \mathrm{kg}$ intramuscularly) and midazolam ( $1 \mathrm{mg} / \mathrm{kg}$ intramuscularly), and muscular paralysis was maintained with pancuronium bromide $(0.1 \mathrm{mg} / \mathrm{kg}$ intravenously). After endotracheal intubation, the animals received positive-pressure ventilation with
$100 \%$ oxygen; anesthesia was maintained with isoflurane (1.1\%-1.2\%). An arterial catheter was positioned in the left femoral artery. Thermodilution catheters (CritiCath, 7F; Ohmeda $\mathrm{GmbH} \& \mathrm{Co}$, Erlangen, Germany) were placed in the femoral vein to allow blood sampling, pressure monitoring in the pulmonary artery, and the recording of cardiac output. An intracranial temperature probe was placed through a drill hole in the epidural space. The drill hole was positioned $1 \mathrm{~cm}$ to the right of a sagittal joint above a parietal line. Other temperature probes were placed in the esophagus and rectum, and a $10 \mathrm{~F}$ catheter was placed in the urinary bladder to monitor urine output.

Electroencephalographic monitoring. Cortical electrical activity, the electroencephalogram (EEG), was registered from 4 stainless steel screw electrodes ( $5 \mathrm{~mm}$ in diameter) implanted in the skull over the parietal and frontal areas of the cortex. These electrodes were referenced to a frontal screw electrode, which together with a ground screw electrode was implanted over the frontal sinuses. A digital EEG recorder (Nervus; Reykjavik, Iceland) and an amplifier (Magnus EEG 32/8; Reykjavik, Iceland) were used in recording, with sampling frequency $1024 \mathrm{~Hz}$ and bandwidth 0.03 to $256 \mathrm{~Hz}$. Continuous baseline EEG was recorded over a period of 10 minutes half an hour after induction of anesthesia. Isoflurane anesthesia was adjusted so that the EEG showed a burst-suppression pattern, that is, high-amplitude EEG bursts interrupted by low-amplitude suppressions. Isoflurane concentration in inflow gas was adjusted to level to $1.1 \%$ to $1.2 \%$ throughout recording. Approximately 90 minutes from the start of drug administration, the second EEG was recorded at normothermia. A continuous EEG was recorded from the beginning of rewarming until $4 \frac{1}{2}$ hours. The bursts disappeared as a result of HCA. After rewarming, the bursts became longer and increased in number and duration, approaching the baseline level in the best case. The total duration of burst measurement interval was calculated at baseline and then repeatedly during rewarming. The ratio of burst durations at these points, divided by the duration at baseline, was used as a simple quantitative measure of EEG recovery.

Cardiopulmonary bypass. Through a right thoracotomy in the fourth intercostal space, the right thoracic artery was ligated and the heart and great vessels were exposed. A membrane oxygenator (Midiflow D 705; Dideco, Mirandola, Italy) was primed with $1 \mathrm{~L}$ of Ringer acetate and heparin (5000 IU). After heparinization (300 IU/kg), the ascending aorta was cannulated with a $16 \mathrm{~F}$ arterial cannula and the right atrial appendage with a single $24 \mathrm{~F}$ atrial cannula. Nonpulsatile cardiopulmonary bypass (CPB) was initiated at a flow rate of $100 \mathrm{~mL} / \mathrm{kg}$ per minute and the flow was adjusted to maintain a perfusion pressure of $50 \mathrm{~mm} \mathrm{Hg}$. A $12 \mathrm{~F}$ intracardiac sump cannula was positioned in the left ventricle for decompression of the left side of the heart during CPB. A heat exchanger was used for core cooling. The $\mathrm{pH}$ was maintained, by alpha-stat principles, at $7.40 \pm 0.05$ with an arterial $\mathrm{PCO}_{2}$ of 4.0 to $5.0 \mathrm{kPa}$, uncorrected for temperature. All measurements were performed at $37^{\circ} \mathrm{C}$. 
A cooling period of 60 minutes was carried out to attain a rectal temperature of $20^{\circ} \mathrm{C}$. The ascending aorta was crossclamped. Cardiac arrest was induced by injecting potassium chloride $(1 \mathrm{mEq} / \mathrm{kg})$ via the aortic cannula, and topical cardiac cooling was maintained throughout the aortic crossclamp period.

Experimental protocol. After cooling to $20^{\circ} \mathrm{C}$, a 75 minute interval of HCA with the head packed in ice was conducted. After this, CPB rewarming was started. The left ventricular vent cannula was removed. Weaning from CPB occurred approximately 60 minutes after the start of rewarming with administration of furosemide $(40 \mathrm{mg})$, mannitol (15.0 g), methylprednisolone (80 mg), and lidocaine (40-150 $\mathrm{mg}$ ). Cardiac support was provided by dopamine. The animals were kept in isoflurane anesthesia until the following morning, extubated, and moved into a recovery room.

During the experiments, hemodynamic and metabolic measurements were recorded at 5 time points as follows: at baseline; at the end of cooling (at $20^{\circ} \mathrm{C}$ ); during rewarming (at $30^{\circ} \mathrm{C}$ ); and 2 and 4 hours after the start of rewarming.

Postoperative evaluation. Postoperatively, all the animals were evaluated daily by an experienced observer (J.R.) who was blinded to the treatment assignment. The examiner used a species-specific quantitative behavioral score as reported earlier. $^{9}$ The assessment quantified mental status $(0=$ comatose, 1 = stuporous, $2=$ depressed, $3=$ normal $)$, appetite $(0=$ refuses liquids, $1=$ refuses solids, $2=$ decreased, $3=$ normal), and motor function $(0=$ unable to stand, $1=$ unable to walk, 2 = unsteady gait, $3=$ normal). Numeric summing of these functions provides a final score: the maximum (score of 9) reflects apparently normal neurologic function, whereas lower values indicate substantial neurologic damage. A score of 8 means that the animals were able to stand unassisted and were likely to recover fully.

Each surviving animal was electively put to death on day 7 after the operation. The entire brain was immediately harvested, weighed, and taken for subsequent histologic analysis.

Histopathologic analysis. During autopsy the brain was excised immediately and the hemispheres were separated. One half was immersed in 10\% neutral formalin and allowed to fix for 2 weeks en bloc. Coronal samples 3-mm thick were sliced from the frontal lobe, thalamus (including the adjacent cortex), and hippocampus (including the adjacent brain stem and temporal cortex), and sagittal samples were sliced from the posterior brain stem (medulla oblongata and pons) and cerebellum. The pieces were fixed in fresh formalin for another week. After fixation, the samples were processed as follows: rinsing in water for 20 minutes and immersion in $70 \%$ ethanol for 2 hours, in $94 \%$ ethanol for 4 hours, and in absolute ethanol for 9 hours. Thereafter, the pieces were kept 1 hour in an absolute ethanol-xylene mixture, 4 hours in xylene, and embedded in warm paraffin wax for 6 hours. The samples were sectioned at $6 \mu \mathrm{m}$ and stained with hematoxylin-eosin. The sections of the brain samples from each animal were screened by a single experienced senior pathologist (J.H.) unaware of the experimental design and the iden- tity and fate of individual animals. Each section was carefully investigated for the presence or absence of any ischemic or other damage.

Visual estimation of the injuries in the sampled regions was as follows: $0=$ no morphologic damage identified, $1=$ edema and/or occasional dark neurons, 2 = numerous dark neurons (often also shrunk) and eosinophilic or dark/shrunken cerebellar Purkinje cells or hemorrhages, and $3=$ clearly infarctive foci with neoformation of capillaries, presence of macrophages, and a glial reaction.

So that semiquantitative comparisons could be made between the animals, a total histologic score was calculated by adding all the regional scores. A score more than 4 means that the animal had a distinct brain injury.

Serum S-100 . Concentrations of serum S-100 $\beta$ were determined in mixed venous blood samples by means of a luminescence immunoassay kit (Sangtec-100, LIA-mat; Sangtec Medical AB, Bromma, Sweden). Serum S- $100 \beta$ protein levels were measured preoperatively and 2 hours, 4 hours, 7 hours, and 20 hours after the start of rewarming.

Other measurements. Systemic arterial and venous blood samples were obtained to determine $\mathrm{pH}, \mathrm{Po}_{2}, \mathrm{PCO}_{2}$, oxygen saturation, oxygen content, hematocrit value, and hemoglobin and glucose concentrations (Ciba-Corning 288 Blood Gas System; Ciba-Corning Diagnostic Corp, Medfield, Mass). Lactate was analyzed with a YSI 1500 analyzer (Yellow Springs Instrument Co, Yellow Springs, Ohio). Hemodynamics, temperatures, and respiratory gases were monitored by the Datex AS/3 anesthesia monitor (Datex Inc, Espoo, Finland).

Statistical analysis. Summary statistics for continuous or ordinal variables are expressed as the median with interquartile range (IQR, 25th and 75th percentile) or means with standard deviation (SD). In the figures, values are shown as medians with IQR. The $t$ test assumptions (normality or equality of variances) were checked first and a corresponding significance test, parametric ( $t$ test), or nonparametric test (MannWhitney $U$ test) was used. One-tailed $P$ values were reported where appropriate. Longitudinal analysis was performed by 2-way analysis of variance. Also, visual evaluation of time series was done to determine interactions between time and protocol. Comparison between each time point and baseline (reference category) was performed by paired samples $t$ test or Wilcoxon matched pairs signed rank test. Again, normality assumptions were tested first. Significance levels are reported for comparisons with $P<.05$. However, the levels of statistical significance should be interpreted with caution, given the large number of statistical tests performed. Analyses were performed with a standard commercially available statistical program (SPSS version 8.0; SPSS Inc, Chicago, Ill).

\section{Results}

\section{Physiologic data}

Comparability of experimental groups. The mean $( \pm$ SD) weight of the animals in the lamotrigine group was 
Table I. Hemodynamic data, blood gases, and hematocrit values in 16 pigs undergoing either lamotrigine $(20 \mathrm{mg} / \mathrm{kg})$ or placebo administration before a 75-minute period of HCA

\begin{tabular}{|c|c|c|c|c|c|c|c|c|c|c|c|}
\hline \multirow[b]{2}{*}{ Group } & \multirow[b]{2}{*}{$N$} & \multirow{2}{*}{\multicolumn{2}{|c|}{$\begin{array}{c}\text { Baseline } \\
\left(37^{\circ} \mathrm{C}\right)\end{array}$}} & \multirow{2}{*}{\multicolumn{2}{|c|}{$\begin{array}{c}\text { End of } C P B \\
\text { cooling }\left(20^{\circ} \mathrm{C}\right)\end{array}$}} & \multicolumn{6}{|c|}{ After start of rewarming } \\
\hline & & & & & & \multicolumn{2}{|r|}{$\left(30^{\circ} \mathrm{C}\right)$} & \multicolumn{2}{|c|}{ Two hours } & \multicolumn{2}{|c|}{ Four hours } \\
\hline \multicolumn{12}{|l|}{ MAP (mm Hg) } \\
\hline Lamotrigine & 8 & 74 & $(68-75)$ & 54 & $(50-57) \ddagger$ & 54 & $(50-57) \ddagger$ & 55 & $(53-57) \ddagger$ & 62 & $(53-67)^{*}$ \\
\hline Placebo & 8 & 77 & $(76-81)$ & 56 & $(54-58) \ddagger$ & 56 & $(52-59) \ddagger$ & 59 & $(49-70)^{*}$ & 70 & $(67-73)^{*}$ \\
\hline \multicolumn{12}{|c|}{ Cardiac output/CPB flow (L/min) } \\
\hline Lamotrigine & 8 & 3.5 & $(3.2-4.0)$ & 2.4 & $(2.2-3.0)$ & 2.5 & $(2.4-2.5)$ & 4.4 & $(4.1-5.0)$ & 3.8 & $(3.4-4.0)$ \\
\hline Placebo & 8 & 3.6 & $(3.5-4.5)$ & 2.5 & $(2.1-3.0)$ & 2.6 & $(2.4-2.7)$ & 3.9 & $(3.7-4.6)$ & 3.1 & $(2.7-3.3)^{*}$ \\
\hline \multicolumn{12}{|l|}{ Arterial $\mathrm{pH}$} \\
\hline Lamotrigine & 8 & 7.49 & (7.46-7.51) & 7.40 & $(7.32-7.46)^{*}$ & 7.41 & $(7.38-7.46)^{*}$ & 7.30 & $(7.27-7.33) \ddagger$ & 7.42 & $(7.37-7.44) \dagger$ \\
\hline Placebo & 8 & 7.47 & $7(7.45-7.50)$ & 7.43 & $(7.36-7.48)$ & 7.49 & $(7.42-7.51)$ & 7.31 & $(7.29-7.32) \ddagger$ & 7.41 & $(7.35-7.43)^{*}$ \\
\hline \multicolumn{12}{|c|}{ Arterial $\mathrm{PCO}_{2}(\mathrm{~mm} \mathrm{Hg})$} \\
\hline Lamotrigine & 8 & 38.9 & $(37.2-42.5)$ & 41.5 & $(37.0-45.1)$ & 27.7 & $(25.0-29.3) \ddagger$ & 46.6 & $(40.7-47.9)^{*}$ & 46.4 & $(41.6-48.3)^{*}$ \\
\hline Placebo & 8 & 42.2 & $2(38.4-44.6)$ & 39.5 & $(33.5-48.2)$ & 24.8 & $(23.3-26.6) \ddagger$ & 46.0 & $(45.2-54.0)^{*}$ & 46.5 & $(44.9-49.7)^{*}$ \\
\hline \multicolumn{12}{|l|}{ Hematocrit } \\
\hline Lamotrigine & 8 & 25.2 & $2(24.6-26.0)$ & 16.7 & $(15.8-17.8) \ddagger$ & 18.5 & $(17.7-19.4) \ddagger$ & 24.9 & $(22.7-26.4)$ & 25.8 & $(23.8-27.7)$ \\
\hline Placebo & 8 & 29.1 & $1(26.5-29.3)$ & 18.5 & $(16.5-19.9) \ddagger$ & 18.2 & $(17.8-20.6) \ddagger$ & 25.0 & $(22.9-25.3)$ & 26.7 & $(25.2-27.1)$ \\
\hline
\end{tabular}

$M A P$, Mean arterial pressure; $C P B$, cardiopulmonary bypass; $P_{C O}$, carbon dioxide tension. Values are shown as medians with IQR.

$* P<.05$ compared with baseline.

$\dagger P<.01$ compared with baseline.

$\ddagger P<.001$ compared with baseline.

Table II. Venous lactate levels, oxygen extraction, and oxygen consumption during the experiment in 16 pigs undergoing either lamotrigine $(20 \mathrm{mg} / \mathrm{kg})$ or placebo administration before a 75-minute period of HCA

\begin{tabular}{|c|c|c|c|c|c|c|}
\hline \multirow[b]{2}{*}{ Group } & \multirow[b]{2}{*}{$N$} & \multirow{2}{*}{$\begin{array}{c}\text { Baseline } \\
\left(37^{\circ} \mathrm{C}\right)\end{array}$} & \multirow{2}{*}{$\begin{array}{c}\text { End of } C P B \\
\text { cooling }\left(20^{\circ} \mathrm{C}\right)\end{array}$} & \multicolumn{3}{|c|}{ After start of rewarming } \\
\hline & & & & $\left(30^{\circ} \mathrm{C}\right)$ & Two hours & Four hours \\
\hline \multicolumn{7}{|c|}{ Venous lactate $(\mathrm{mmol} / \mathrm{L})$} \\
\hline Lamotrigine & 8 & $1.05(1.04-1.42)$ & $2.14(2.02-2.43) \dagger$ & $7.16(6.56-7.45) \ddagger$ & $5.60(5.17-6.49) \ddagger$ & $2.65(2.31-3.06) \dagger$ \\
\hline Placebo & 8 & $0.98(0.75-1.07)$ & $1.84(1.49-1.97) \dagger$ & $6.96(5.92-7.23) \ddagger$ & $6.07(3.31-8.11) \ddagger$ & $1.82(1.09-4.21)^{*}$ \\
\hline \multicolumn{7}{|c|}{ Oxygen extraction (mL/dL) } \\
\hline Lamotrigine & 8 & $2.7 \quad(2.5-3.2)$ & $1.5 \quad(0.7-2.2) \ddagger$ & $2.7 \quad(2.7-3.0)$ & $2.3 \quad(2.2-2.9)$ & $2.7 \quad(2.7-2.8)$ \\
\hline Placebo & 8 & $2.6 \quad(1.7-2.8)$ & $1.4 \quad(1.2-1.7) \ddagger$ & $\begin{array}{c}3.3 \quad(3.1-3.4) \\
P=.001\end{array}$ & $\begin{array}{c}2.8 \quad(2.8-3.6) \\
P=.03\end{array}$ & $\begin{array}{c}3.7 \quad(3.4-4.2)^{*} \\
P=.01\end{array}$ \\
\hline \multicolumn{7}{|c|}{ Oxygen consumption (mL/min) } \\
\hline Lamotrigine & 8 & $100.3(84.4-109.8)$ & $33.0 \quad(19.5-47.8) \ddagger$ & $70.0 \quad(68.2-76.2)$ & $103.7(95.7-123.5)$ & $105.6(92.3-111.4)$ \\
\hline Placebo & 8 & $80.3 \quad(68.1-113.4)$ & $33.0 \quad(28.4-41.6) \ddagger$ & $\begin{array}{c}81.5 \quad(75.8-87.5) \\
P=.04\end{array}$ & $128.2(113.8-139.0)^{*}$ & $108.8(98.0-143.4)$ \\
\hline
\end{tabular}

For abbreviations see Table I. Values are shown as medians with IQRs.

$* P<.05$ compared with baseline.

$\dagger P<.01$ compared with baseline.

$\ddagger P<.001$ compared with baseline.

$23 \pm 1 \mathrm{~kg}$ and in the placebo group $24 \pm 2 \mathrm{~kg}(P>.2)$. The mean $( \pm \mathrm{SD}) \mathrm{CPB}$ cooling time in the lamotrigine group was $61 \pm 3$ minutes and in the placebo group $62 \pm 4$ minutes $(P>.2)$. Rewarming time in the lamotrigine group was $68 \pm 6$ minutes and in the placebo group $70 \pm 12$ minutes $(P>.2)$. Temperatures during the experimental period did not differ between the groups.

Hemodynamic data. All animals were in stable condition before, during, and after $\mathrm{CPB}$, although mean arteri- al pressure remained below baseline levels after the period of HCA. No significant differences in hemodynamic measurements between the groups were found (Table I).

Blood gas and hematocrit measurements. Blood gas and hematocrit measurements are shown in Table I. The lamotrigine group showed a decrease in $\mathrm{pH}$ at the end of cooling and during rewarming when $30^{\circ} \mathrm{C}$ was reached, compared with baseline $(P<.05)$. Both groups showed decreased $\mathrm{pH}$ at 2 and 4 hours after the 
start of rewarming when compared with baseline $(P<.05)$. There were no significant differences between the groups. Arterial $\mathrm{PCO}_{2}$ was higher in both groups 2 and 4 hours after the start of rewarming compared with baseline $(P<.05)$.

Metabolic data. Venous lactate levels increased during cooling, especially after intervention, in both groups. Oxygen extraction was higher after the start of rewarming in the placebo group than in the lamotrigine group. Oxygen consumption was higher in the placebo group when $30^{\circ} \mathrm{C}$ was reached during rewarming compared with the lamotrigine group $(P=.04)$ (Table II).

EEG. There was no significant difference between the groups at recording points before and after drug administration or within the groups. At the baseline, median (IQR) of burst-suppression ratio, that is, highamplitude EEG bursts interrupted by low-amplitude suppressions, was $0.29(0.22-0.49)$ in the lamotrigine group and $0.45(0.35-0.60)$ in the placebo group $(P=$ .29). After drug administration, these values were 0.26 (0.19-0.51) and $0.43(0.36-0.68)(P=.07)$, respectively. When EEG activity after drug administration was compared with baseline, $P$ value was .47 in the lamotrigine group and .15 in the placebo group. The percent of EEG burst recovery compared with baseline is shown at Fig 1. This recovery was found to be higher in the lamotrigine group, the median being $40 \%$ compared with $17 \%$ in the placebo group at 4 hours $(P=$ .02 ) and $80 \%$ compared with $20 \%$ at $4 \frac{1}{2}$ hours after the start of rewarming $(P=.01)$.

Morbidity and mortality. All animals were in stable condition during the surgical procedures and survived to at least the first postoperative day. Eleven of the 16 animals (69\%) survived 7 days after the operation and were electively put to death. In the lamotrigine group, 6 of $8(75 \%)$ animals survived 7 days compared with 5 of $8(63 \%)$ in the placebo group $(P>.2)$ (Table III). During the autopsy of the animals that died on the first postoperative day, severe lung congestion (lamotrigine group, $\mathrm{n}=1$ ) and acute myocardial infarction (placebo group, $n=1$ ) were the causes of death. Three animals (lamotrigine, $\mathrm{n}=1$; placebo, $\mathrm{n}=2$ ) died of severe brain damage and were not able to breath. During the autopsy, significant brain edema, especially in the cerebellum and brain stem, was detected.

Behavioral outcome. The results of behavioral scoring for both groups are shown in Fig 2. A score of 8 or 9 indicates essentially complete neurologic recovery. Animals that died early were given a score of 0 beginning at the time of death. Complete behavioral recovery was seen in 5 of $8(63 \%)$ animals after lamotrigine administration, compared with 1 of $8(13 \%)$ animals in

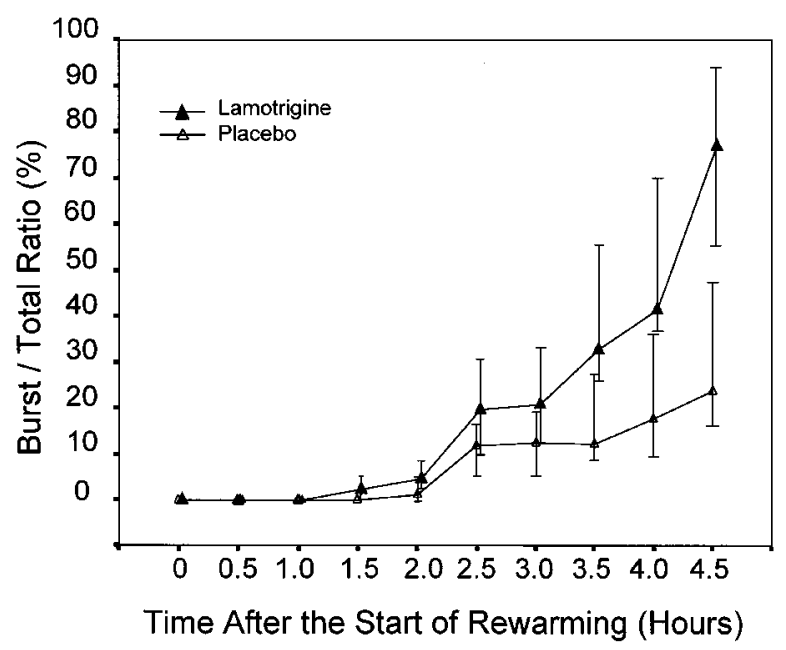

Fig 1. Medians with IQRs of total EEG burst ratios (relative to baseline) of 16 pigs undergoing either lamotrigine or placebo administration before a 75-minute period of HCA. EEG bursts recovered significantly better in the lamotrigine group 4 hours after the start of rewarming than in the placebo group $(P<.05)$.

the placebo group $(P=.02)$. Among the animals that survived for 7 days, the median behavioral score was higher in the lamotrigine group (8) than in the control group (7) $(P=.02)$.

Histopathologic results. The median of total histopathologic score in the lamotrigine group was 5.5 and in the placebo group $7.5(P=.06)$ (Fig 3). The median histopathologic score in the hippocampus was lower in the lamotrigine group (0) than in the placebo group (0.5), although this difference was not statistically significant $(P=.09)$ (Table III).

S-100 $\beta$. An average 3-fold increase in S-100 $\beta$ levels in both groups compared with baseline was seen 2 hours after the start of rewarming $(P=.01)$. The median $\mathrm{S}-100 \beta$ concentration remained at a lower level in the lamotrigine group, being statistically significant 20 hours after the start of rewarming $(0.1 \mu \mathrm{g} / \mathrm{L}$ vs 0.03 $\mu \mathrm{g} / \mathrm{L} ; P=.01)($ Fig 4$)$.

\section{Discussion}

The results of this study indicate that lamotrigine may improve cerebral outcome after a prolonged period of HCA. The better outcome was seen in terms of neurophysiologic, behavioral, S-100 $\beta$, and histopathologic data. The results confirm those of previous studies suggesting that lamotrigine has neuroprotective effects. ${ }^{8}$ This study is the first to report a possible benefit of lamotrigine during HCA. 


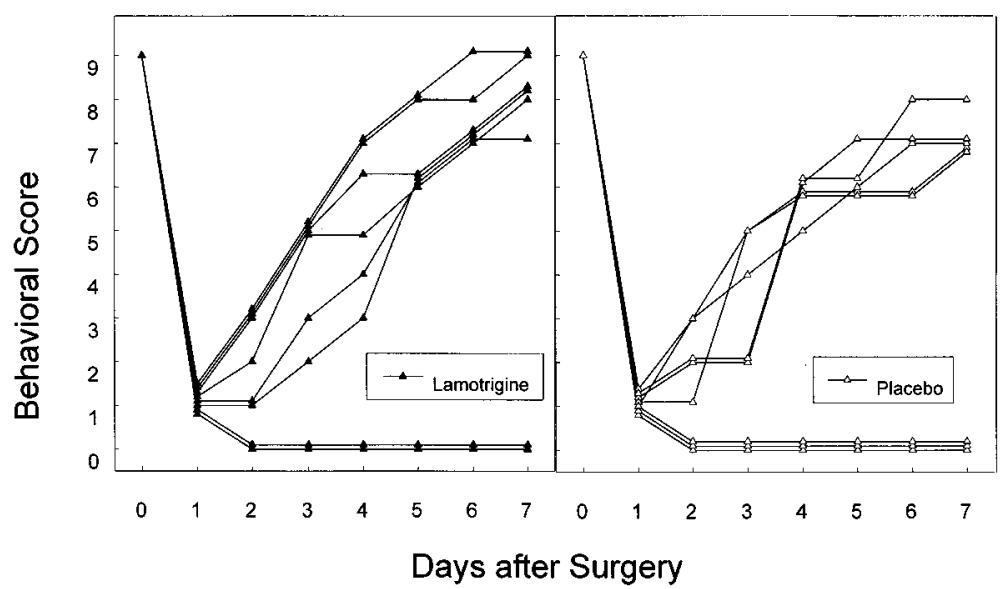

Fig 2. Daily scores indicating behavioral recovery after interventions. A score of 8 or 9 indicates essentially complete recovery, lower scores indicate substantial impairment, and 0 indicates coma or death. Behavioral scores on day 7 after the operation among the surviving animals showed a significant difference between the groups $(P=.02)$.

Table III. Histopathologic scores and survival after the experiment in 16 pigs undergoing either lamotrigine (20 $\mathrm{mg} / \mathrm{kg}$ ) or placebo administration before a 75-minute period of $\mathrm{HCA}$

\begin{tabular}{|c|c|c|c|c|c|c|c|c|}
\hline Protocol & Pig No. & Survival $(d)$ & Cortex & Thalamus & Hipросатриs & Posterior brain stem & Cerebellum & Total score \\
\hline \multirow[t]{8}{*}{ Lamotrigine } & 1 & 1 & 2 & 0 & 0 & 2 & 0 & 4 \\
\hline & 2 & 7 & 1 & 0 & 0 & 1 & 1 & 3 \\
\hline & 3 & 1 & 2 & 2 & 0 & 2 & 0 & 6 \\
\hline & 4 & 7 & 0 & 0 & 0 & 2 & 2 & 4 \\
\hline & 5 & 7 & 3 & 0 & 0 & 1 & 1 & 5 \\
\hline & 6 & 7 & 3 & 0 & 0 & 2 & 1 & 6 \\
\hline & 7 & 7 & 3 & 3 & 1 & 2 & 2 & 11 \\
\hline & 8 & 7 & 2 & 1 & 1 & 2 & 1 & 7 \\
\hline \multirow[t]{8}{*}{ Placebo } & 1 & 7 & 3 & 2 & 0 & 2 & 1 & 8 \\
\hline & 2 & 7 & 2 & 2 & 2 & 2 & 0 & 8 \\
\hline & 3 & 7 & 2 & 0 & 0 & 1 & 1 & 4 \\
\hline & 4 & 7 & 2 & 0 & 2 & 2 & 1 & 7 \\
\hline & 5 & 1 & 2 & 2 & 1 & 2 & 2 & 9 \\
\hline & 6 & 7 & 3 & 2 & 0 & 2 & 0 & 7 \\
\hline & 7 & 1 & 1 & 0 & 0 & 2 & 2 & 5 \\
\hline & 8 & 1 & 1 & 2 & 2 & 2 & 1 & 8 \\
\hline
\end{tabular}

Scores: $O=$ no morphologic damage; $1=$ edema and/or occasional dark neurons; 2 = numerous dark neurons and eosinophilic or dark/shrunk cerebellar Purkinje cells or hemorrhages; 3 = clearly infarctive foci.

Hypothermia is known to produce a significant decrease in $\mathrm{CMRO}_{2}$, increasing the permissible period of HCA. ${ }^{10}$ However, even in deep hypothermia $\left(10^{\circ}\right.$ $15^{\circ} \mathrm{C}$ ), a significant degree of $\mathrm{CMRO}_{2}$ remains and the duration of safe HCA is limited to 40 to 50 minutes. ${ }^{3}$ Previous studies suggest that energy failure itself is not particularly toxic to neurons. ${ }^{6}$ What makes it neurotoxic is subsequent failure of neurotransmitter transport. The ischemic injury begins with depolarization of the presynaptic membrane mediated by the metabolic fail- ure of voltage-sensitive $\mathrm{Na}^{+}$channels that carry electrical messages to the synapse. Depolarization leads to secretion of neurotransmitters (glutamate). In the normal environment, after release into the intercellular space, glutamate is rapidly converted to glutamine and re-enters the neuron ready to be used for the next message. Because of depletion of cellular energy during ischemia, the high affinity of glutamate is compromised. This interrupts the conversion of glutamate to glutamine and leads to its accumulation in the intercel- 


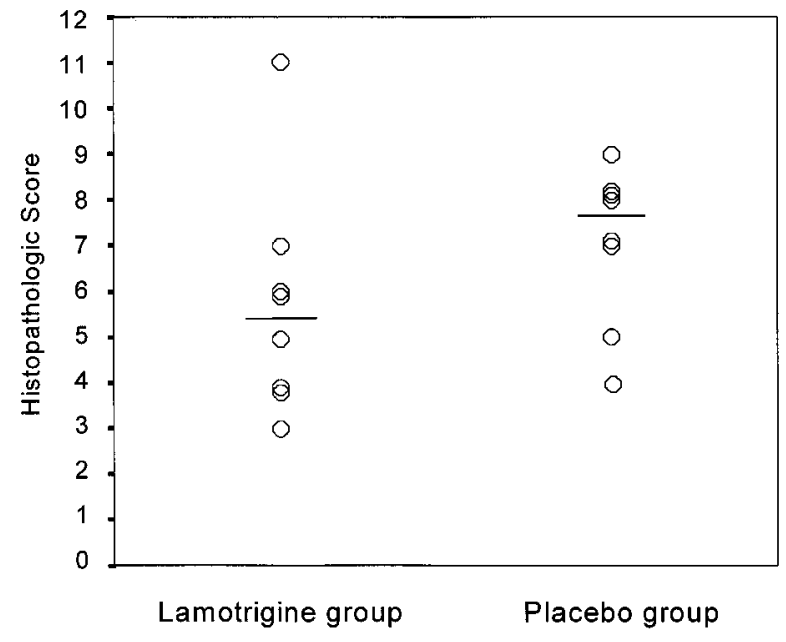

Fig 3. Total histopathologic scores among 16 pigs undergoing either lamotrigine or placebo administration before a 75minute period of HCA. The total histopathologic score was calculated by adding the quantitative assessment of histopathologic findings in the investigated regions of the brain for each of the animals. The scores in the lamotrigine group were lower than in the placebo group $(P=.06)$.

lular space, where it acts as a potent neurotoxic substance. It opens calcium channels, leading to an influx of calcium, which starts the catastrophic intracellular activation of protease, lipase, and kinase $\mathrm{C}$, along with altered transcription and release of free oxygen radicals, that eventually leads to neuronal autodigestion and cell death. ${ }^{6}$

This knowledge has opened up new avenues of research to improve current methods to protect the brain during ischemia. If this biochemical cascade could be blocked by a suitable antagonist, the neurons might survive a period of depletion of oxygen and metabolites. The most frequently studied antagonists are the glutamate receptor blockers and $\mathrm{Ca}^{2+}$ and $\mathrm{Na}^{+}$ channel antagonists. ${ }^{11-13}$ Despite promising results in experimental studies with various specific interventional agents, most of these have turned out to be neurotoxic in a clinical setting, and trials have been stopped due to side effects, such as sympatholytic effects of SNX-111, nefrotoxicity of NBQX, and hallucinogenic properties of MK-801. ${ }^{14}$ The reason to test lamotrigine in the present study was that it is safely used clinically as an antiepileptic drug. Its proposed mechanism is prevention of $\mathrm{Na}^{+}$-dependent depolarization and subsequent neurotransmitter release. ${ }^{14}$

Lamotrigine is rapidly absorbed, and the bioavailability of the oral formulation is about 98\%. Peak serum levels are reached within 3 hours. The concen-

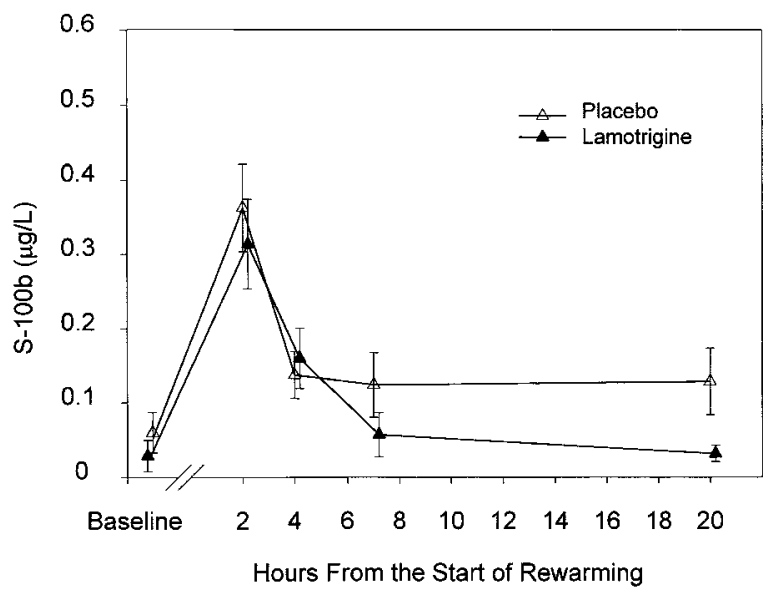

Fig 4. S-100 $\beta$ levels of 16 pigs undergoing either lamotrigine or placebo administration before a 75-minute period of HCA. S- $100 \beta$ levels were lower in the lamotrigine group 20 hours after the start of rewarming $(P=.01)$. Two hours after the start of rewarming, S-100 $\beta$ levels were higher than at baseline $(P=.03)$. Values are shown as medians with IQRs.

tration of lamotrigine is the same in brain and plasma, mean half-life being 23 to 37 hours. ${ }^{15}$ The present dose of lamotrigine was higher than recommended in antiepileptic medication, but this dose should also be tolerated by human beings. Histopathologic evaluation 4 days after 5 and 15 minutes of a global ischemia in gerbils in normothermia demonstrated neuroprotective efficacy of lamotrigine $(100 \mathrm{mg} / \mathrm{kg}) .{ }^{16}$ In another study with gerbils, improved protection was demonstrated histologically at 7 and 28 days after focal ischemia in animals treated with lamotrigine before and after insult. $^{8}$

The survivals in the current study were $75 \%$ in the lamotrigine group and $63 \%$ in the placebo group. In terms of behavioral assessment, however, a better outcome was seen in the lamotrigine group. Among the animals that survived for 7 days, the behavioral score was better in the lamotrigine group. The median score of 8 in lamotrigine-treated animals indicates a mild disturbance or full recovery. Control animals showed more severe initial neurologic impairment, and only 1 control animal recovered to a score of 8 .

EEG bursts recovered better in the lamotrigine group at 4 hours after the start of rewarming than in the placebo group. Ischemic brain damage, surgical disconnection of cortical blocks, and several anesthetics are known to produce burst suppression in EEG. The effects of anesthetics and brain damage are additive. ${ }^{17}$ 
In the present study, the additive effect of ischemic damage plus isoflurane-produced burst suppression proved to be a sensitive measure of recovery. The bursts are readily detected and their duration can be measured even when EEG recordings are very low in amplitude as a result of hypothermia, close to the noise level of the recording system, when other quantification of EEG recordings is questionable. The EEG recovery was in line with other measures of brain damage, suggesting that it correctly reflects the neuroprotective effect of lamotrigine. It may also be able to accurately pinpoint the time when lamotrigine-protected brains are recovering better than those in the placebo group. Our previous studies, using EEG, have also suggested that approximately 3 hours after HCA a change in brain electrical activity correctly distinguishes between pigs that will have severe damage and those that will fare better. ${ }^{18}$ Whether this kind of monitoring can be used in a clinical setting to identify those patients in whom special measures should be carried out for brain protection remains to be seen.

The S-100 protein is a small dimetric cytosolic protein that exists in various forms depending on its chain ( $\alpha$ or $\beta$ ) structure. The $\beta \beta$ form predominantly occurs in astroglial and Schwann cells and the $\alpha \beta$ form in astroglial cells, the concentrations in other cells being negligible. S-100 protein is involved in promoting axonal growth, glial proliferation, neuronal differentiation, and calcium homeostasis. ${ }^{19}$ Increased levels of S-100 protein have been measured after cardiac operations, stroke, and several other neurologic disorders. ${ }^{20,21}$ This marker has been enthusiastically adopted for clinical use by many cardiac surgeons, with the expectation that repeated measurements could indicate brain injury postoperatively. ${ }^{20}$ In the present study, in response to ischemic brain insult, S-100 $\beta$ levels increased significantly shortly after the start of rewarming in both of the groups. The finding that S-100 $\beta$ concentrations decreased to a lower level on day 1 after the operation in lamotrigine-treated animals is in line with other outcome data and supports the findings of better brain protection in these animals compared with controls.

Our findings are supported by a recent article demonstrating that lamotrigine has an effect on glutamate release in the pig. The most likely mechanism leading to improved neurologic outcome seen in the current study after lamotrigine treatment is the inhibition of glutamate release. ${ }^{22}$ Several differences exist in the experimental design between these 2 studies, however, making further comparisons difficult. The major limitation in this respect is that animals were exposed to 15minute periods of global ischemia at normothermia in the previous study. It must be borne in mind that hypothermia per se is the most powerful tool to prevent the release of neurotransmitters. The finding that lamotrigine did not attenuate the release of neurotransmitters at the level of $20 \mathrm{mg} / \mathrm{kg}^{22}$ does not prove that this cannot occur after 3-fold longer periods of ischemia at $20^{\circ} \mathrm{C}$. Their finding is that no improvement in neurologic parameters including EEG recovery, brain lactate, and $S-100 \beta$ protein release is attenuated by the use of an acute model. As seen from the present data, significant differences in EEG recovery and S-100 $\beta$ levels were found several hours after the start of rewarming. Therefore, it seems especially important to remember that laboratory studies that do not include some reliable measures of neurologic outcome must be interpreted with caution.

In conclusion, the present results suggest that the $\mathrm{Na}+$ channel blocker lamotrigine improves neurologic outcome after a prolonged period of HCA.

We express our sincere gratitude to Randall B. Griepp, MD, who generously permitted us to use this animal model; Ari Ahola, MD, and Simon Lister, PhD, from GlaxoWellcome for providing lamotrigine; Osmo Hormi, $\mathrm{PhD}$, and Anu Moilanen, $\mathrm{PhD}$, from the Department of Chemistry, Oulu University, for preparing the isethionate salt of lamotrigine; Sirpa Ämmälä, MSc (Pharm), and Outi Ryymin, MSc (Pharm), for preparing and randomizing the ampules; Seija Seljänperä, RN, Veikko Lähteenmäki, and Kauko Korpi, RN, for technical assistance; and Pasi Ohtonen, MSc, medical biostatistician, for help in statistical analysis.

\section{REFERENCES}

1. Griepp RB, Stinson EB, Hollingsworth JF, Buehler D. Prosthetic replacement of the aortic arch. J Thorac Cardiovasc Surg 1975;70:1051-63.

2. Griepp RB, Ergin MA, McCullough JN, et al. Use of hypothermic circulatory arrest for cerebral protection during aortic surgery. J Card Surg 1997;12( Suppl):312-21.

3. McCullough JN, Zhang N, Reich D, et al. Cerebral metabolic suppression during hypothermic circulatory arrest in humans. Ann Thorac Surg 1999;67:1895-9.

4. Choi DW, Rothman SM. The role of glutamate neurotoxicity in hypoxic-ischemic neuronal death. Annu Rev Neurosci 1990;13:171-82

5. Garcia JH, Anderson ML. Physiopathology of cerebral ischemia. Crit Rev Neurobiol 1989;4:303-24.

6. Lipton SA, Rosenberg PA. Excitatory amino acids as a final common pathway for neurologic disorders. $N$ Engl J Med 1994;330:613-22.

7. Bacher A, Zornow MH. Lamotrigine inhibits extracellular glutamate accumulation during transient global cerebral ischemia in rabbits. Anesthesiology 1997;86:459-63.

8. Shuaib A, Mahmood RH, Wishart T, et al. Neuroprotective effects of lamotrigine in global ischemia in gerbils: a histological, 
in vivo microdialysis and behavioral study. Brain Res 1995;702:199-206.

9. Juvonen T, Weisz DJ, Wolfe D, et al. Can retrograde perfusion mitigate cerebral injury following particulate embolization? J Thorac Cardiovasc Surg 1998;115:1142-59.

10. Ginsberg MD, Sternau LL, Globus MY, et al. Therapeutic modulation of brain temperature: relevance to ischemic brain injury. Cerebrovasc Brain Metab Rev 1992;4:189-225.

11. Baumgartner WA, Walinsky PL, Salazar JD, et al. Assessing the impact of cerebral injury after cardiac surgery: Will determining the mechanism reduce this injury? Ann Thorac Surg 1999;67:1871-3.

12. Aoki M, Nomura F, Stromski ME, et al. Effects of MK-801 and NBQX on acute recovery of piglet cerebral metabolism after hypothermic circulatory arrest. J Cereb Blood Flow Metab 1994;14:156-65.

13. Perez-Pinzon MA, Yenari MA, Sun GH, et al. SNX-111, a novel, presynaptic $\mathrm{N}$-type calcium channel antagonist, is neuroprotective against focal cerebral ischemia in rabbits. J Neurol Sci 1997;153:25-31.

14. Small DL, Buchan AM. Mechanisms of cerebral ischemia: intracellular cascades and therapeutic interventions. J Cardiothorac Vasc Anesth 1996;10:139-46.

15. Ramsay RE, Pellock JM, Garnett WR, et al. Pharmacokinetics and safety of lamotrigine (Lamictal) in patients with epilepsy. Epilepsy Res 1991;10:191-200.

16. Wiard RP, Dickerson MC, Beek O, et al. Neuroprotective properties of the novel antiepileptic lamotrigine in a gerbil model of global cerebral ischemia. Stroke 1995;26:466-72.

17. Wennberg R, Quesney F, Olivier A, Dubeau F. Induction of burst-suppression and activation of epileptiform activity after methohexital and selective amygdalo-hippocampectomy. Electroencephalogr Clin Neurophysiol 1997;102:443-51.

18. Anttila V, Kiviluoma K, Pokela M, et al. Cold retrograde cerebral perfusion improves cerebral protection during moderate hypothermic circulatory arrest: a study in a chronic porcine model. J Thorac Cardiovasc Surg 1999;118:938-45.

19. Johnsson P. Markers of cerebral ischemia after cardiac surgery. J Cardiothorac Vasc Anesth 1996;10:120-6.

20. Westaby S, Johnsson P, Parry AJ, et al. Serum S100 protein: a potential marker for cerebral events during cardiopulmonary bypass. Ann Thorac Surg 1996;61:88-92.

21. Buttner T, Weyers S, Postert T, et al. S-100 protein: serum marker of focal brain damage after ischemic territorial MCA infarction. Stroke 1997;28:1961-5.

22. Conroy BP, Black D, Lin CY, et al. Lamotrigine attenuates cortical glutamate release during global cerebral ischemia in pigs on cardiopulmonary bypass. Anesthesiology 1999;90:844-54.

\section{ON THE MOVE? \\ Send us your new address at least six weeks ahead}

Don't miss a single issue of the journal! To ensure prompt service when you change your address, please photocopy and complete the form below.

Please send your change of address notification at least six weeks before your move to ensure continued service. We regret we cannot guarantee replacement of issues missed due to late notification.

JOURNAL TITLE:

Fill in the title of the journal here.

OLD ADDRESS:

Affix the address label from a recent issue of the journal here.
NEW ADDRESS:

Clearly print your new address here.

Name

Address

City/State/ZIP
COPY AND MAIL THIS FORM TO:

Mosby

Subscription Customer Service

6277 Sea Harbor Dr

Orlando, FL 32887
OR FAX TO:

407-363-9661

N/ Mosby
OR PHONE:

800-654-2452

Outside the U.S., call

407-345-4000 